\title{
BMJ \\ open \\ Open versus closed IV infusion systems: a state based model to predict risk of catheter associated blood stream infections
}

\author{
Nicholas Graves, ${ }^{1}$ Adrian G Barnett, ${ }^{1}$ Victor D Rosenthal ${ }^{2}$
}

To cite: Graves N, Barnett AG, Rosenthal VD. Open versus closed IV infusion systems: a state based model to predict risk of catheter associated blood stream infections. BMJ Open 2011;1: e000188. doi:10.1136/ bmjopen-2011-000188

- Prepublication history for this paper is available online. To view these files please visit the journal online (http:// bmjopen.bmj.com).

Received 25 May 2011 Accepted 5 August 2011

This final article is available for use under the terms of the Creative Commons Attribution Non-Commercial 2.0 Licence; see http://bmjopen.bmj.com

\footnotetext{
${ }^{1}$ Institute of Health and Biomedical Innovation and School of Public Health, Queensland University of Technology, Brisbane, Australia

${ }^{2}$ Bernal Medical Center, Colegiales Medical Center, Department of Infectious Diseases and Hospital Epidemiology, Buenos Aires, Argentina

Correspondence to Professor Nicholas Graves: n.graves@qut.edu.au
}

\section{ABSTRACT}

Objectives: To quantify the change in risk of central line associated blood stream infection (CLABSI) following the introduction of a closed infusion container in intensive care units (ICUs) in two Latin American cities.

Design: A state-space model was used to describe the flow of admissions through the ICU. This approach correctly treats infection as a time-dependent covariate.

Results: A closed system reduced the risk of CLABSI. The hazard ratios for the closed versus open container were between 0.15 and 0.31 ( $p$ values $<0.001$ ), indicating a clinically significant reduction in the risk of admissions having a CLABSI. A simulation study showed that a closed system reduced the number of infections, costs and deaths.

Conclusions: The data reveal costs are saved and health benefits gained from fewer cases of CLABSI after adoption of a closed infusion system. Information is required on the costs of implementing the closed system widely in these settings.

\section{INTRODUCTION}

Decisions on how to reduce healthcare acquired infection (HAI) should be informed by reliable data and appropriate analyses. Novel infection control interventions tend to increase costs, but cost savings may result from avoided HAIs because treatment and diagnosis costs are saved and lengths of stay in hospital are shortened. There are also health benefits if cases of infection are prevented and excess morbidity and mortality risk reduced. Economic analyses quantify these changes and provide signals for decision makers.

Little is known about the economics of reducing the risks of HAI in high income countries ${ }^{12}$ where rates of HAI are relatively low. Even less is known about the economics of prevention in middle income settings where rates are relatively high. ${ }^{3-8}$ The aim of

\section{ARTICLE SUMMARY}

\section{Article focus}

- The risks of central line associated blood stream infections among patients in intensive care units (ICUs) in Mexico and São Paulo were examined.

- Risks before and after the introduction of closed infusion containers were compared.

- Simulation studies revealed the impact of the change on the amount of bed days and number of deaths.

\section{Key messages}

- Risks were reduced in both cities after the introduction of closed infusion containers and there was a statistically significant reduction in the number of deaths in both cities.

- A large reduction in bed days was observed in São Paulo but not in Mexico.

- Closed instead of open infusion systems among ICU patients reduces the risks of central line associated blood stream infections, decreases costs and saves lives.

Strengths and limitations of this study

- The fact that observational data were used and other factors may explain the observed reductions in risk. Information on the cost of adopting the closed system was not available but is required to complete the economic argument. The time-dependent covariate of infection was correctly modelled by a state based method; failure to account for timing of infection is an important source of bias. There are few published data on the value of improving infection control in middle income settings where the problem is relatively large and the potential gains substantial.

this paper is to identify reductions in the risk of central line associated blood stream infections (CLABSI) following the implementation of closed infusion containers among admissions to intensive care units (ICUs) in Brazil and Mexico. Analysis of the number of bed days used and deaths occurring under an open and closed infusion container system 
among ICU admissions will provide useful information for infection control decision makers.

\section{METHODS}

Data collection

In this study we used data from ICUs in Brazil and Mexico that were part of the International Nosocomial Infection Control Consortium (INICC). ${ }^{1}$ This is a quality improving activity and this use of the data is exempt from ethics or IRB review. The laboratory techniques used, training programs for data collectors, definitions of infection and surveillance activities are described in detail by Rosenthal et al. ${ }^{1}$ For this analysis, values for the following variables were available: hospital name and location; dates of admission, discharge and death; type and site of HAI; average severity of illness score (ASIS); and age. Data were also available that described time periods, including a lead-in period, before and after the introduction of a closed infusion system. Only data from admissions with a central line are included.

\section{Closed infusion container}

The aim was to examine the effect of a closed versus open infusion container on admissions requiring a central line. The open container uses a glass or semirigid plastic bottle or a burette that is open to the air in order to allow the fluid to exit. ${ }^{2}$ The closed infusion container uses a collapsible plastic bag with no external venting. The fluid in the closed infusion container is protected from any airborne microorganism present in the ICU. Closed infusion containers are standard throughout North America and Western Europe.

\section{Statistical methods}

We used the state-space model shown in figure 1 to model the flow of admissions through the ICU, and hence quantify the effect of the closed infusion container. Admissions started in the susceptible state. After a variable period of time, they either moved straight to the discharged or dead states, or moved to these states after becoming infected. Using the terminology of state-space models, discharge and death are absorbing states, and CLABSI is a transient state. ${ }^{3}$ In figure 1 the arrows are the transitions, and in this model

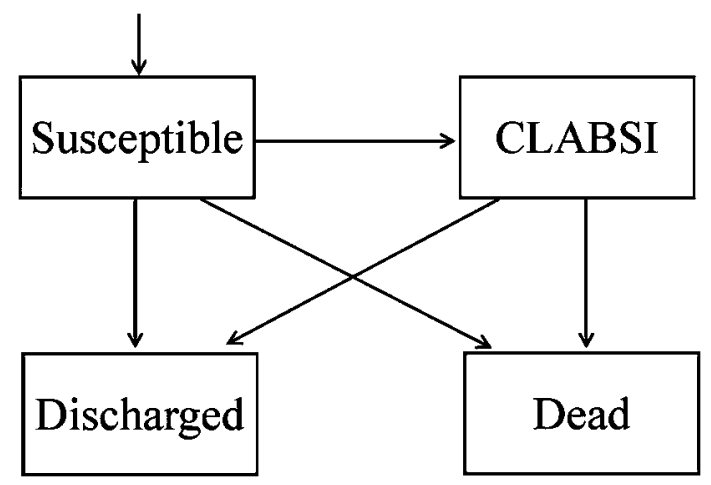

Figure 1 Four-state transition model to model length of stay in an intensive care unit. there are five possible transitions (disregarding the entry transition). The advantage of a state-space model is that CLABSI is correctly treated as a time-dependent covariate, ${ }^{4}$ and we can allow the effects of covariates to change depending on what state the patient is in. Methods that do not correctly classify patient's risks and exposures in time will bias conclusions. Time bias has been shown to always overstate estimates of excess stay and death risk from nosocomial infection. ${ }^{5}$ Barnett et al illustrate the effect of time bias on extra stay and death risk from nosocomial infection. ${ }^{6}$ The dates of the patient's entry, CLABSI infection and final outcome were used to calculate the times spent in each state. If the date of a patient's infection was the same as their date of discharge or death, then we subtracted a half day from the CLABSI date to ensure that they were recorded as visiting the CLABSI state. ${ }^{7}$ We followed the methods described in Putter et al to fit the state-space model, using the 'clock reset' approach and semi-Markov stratified hazards. When this method is used, the effect of a covariate depends on the transition. For example, older age may decrease the risk of a patient moving from the 'susceptible' to 'discharged' states but increase their risk of moving from the 'susceptible' to 'dead' states. We fitted the models using Cox proportional hazards, using the $\mathrm{R}$ statistical package (http://www.r-project.org/), which gives the hazard ratios (HRs) for the covariates. The hazard is the rate at which admissions move from one state to another. The HR describes the relative change in this rate due to a change in the covariate. HRs of 1 indicate no change in risk, HRs $>1$ indicate an increased risk, and HRs $<1$ indicate a reduced risk. CIs and $\mathrm{p}$ values for the HRs are shown.

The intervention of interest was the implementation of the closed versus open infusion system (binary covariate). We adjusted for the continuous covariates of age and ASIS. Older age and higher ASIS are both likely to increase the risk of death and decrease the risk of discharge.

After estimating the changes in risks due to the closed system, we calculated the number of admissions in each state in figure 1 using a simulation study. For the open and closed infusion container we started 1000 admissions in the susceptible state and then followed their movements and times spent in each state until discharge or death. The transition rates were based on the estimates from the Cox proportional hazards models. We incorporated the uncertainty in these rates by allowing the log-hazard rate to have a normal distribution based on the estimated mean and SE. We simulated each set of admissions 5000 times to cover the range of uncertainty. For each simulation, we calculated the differences between the systems in terms of bed days used, admissions infected and admissions dying. We summarised these differences using the mean and 95\% Bayesian credible interval over all 5000 simulations. These simulations were carried out using differential equations in the WBDiff add-on package to WinBUGS. ${ }^{9}$ 
Table 1 Descriptive statistics by city for admissions with a central line

\begin{tabular}{lll}
\hline Dates & $\begin{array}{l}\text { Mexico } \\
\text { June 2002-December 2003 }\end{array}$ & $\begin{array}{l}\text { São Paulo } \\
\text { October 2003-April 2005 }\end{array}$ \\
\hline Number of ICU wards & 4 & 3 \\
Total number of admissions & 1571 & 960 \\
Patient days in ICU & 12651 & 12526 \\
Age (years), mean (SD) & $53(18.6)$ & $54(18.6)$ \\
ASIS, mean (SD) & $3.7(0.97)$ & $3.8(0.83)$ \\
Dead, n (\%) & $353(22)$ & $221(23)$ \\
Admissions with a CLABSI, n (\%) & $168(10.7)$ & $69(7.2)$ \\
CLABSIs per 1000 central line days & 14.4 & 5.9 \\
Central line days & 11667 & 11695 \\
Length of stay (days), median (IQR) & $6(4-10)$ & $6(4-12)$ \\
Admissions with a closed system, n (\%) & $535(33.9)$ & $418(47.8)$ \\
\hline ASIS, acute severity illness score; CLABSI, central line associated blood stream infection; ICU, intensive care unit.
\end{tabular}

For the descriptive statistics of the study sample, we use the mean and SD for continuous variables that were roughly normally distributed, and the median and IQR otherwise.

\section{RESULTS}

Four admissions were excluded because it was not recorded whether they died or were discharged. The characteristics of the remaining admissions are shown in table 1.

There were 2531 ICU admissions where a central line was used at some time, and these admissions spent 25177 days in the ICU. The rate of CLABSIs was highest in Mexico at 14.4 infections per 1000 admissions. The HRs for age, ASIS score and the closed versus open infusion container are shown in table 2.

In Mexico, older admissions were at less risk of becoming infected with a CLABSI (HR 0.87, 95\% CI 0.81 to $0.95, \mathrm{p}=0.001)$. In both cities, a higher ASIS score strongly reduced the risk of moving from 'susceptible' to 'discharged', and so increased length of stay ( $\mathrm{p}$ values $\leq 0.001$ ). In Mexico, a higher ASIS score increased the risk of death. Sicker admissions with a CLABSI had a lower chance of discharge compared with healthier infected admissions, as the $\mathrm{HR}$ for moving from 'CLABSI' to 'discharged' was between 0.54 and 0.76 for every one unit increase in ASIS score.

The closed infusion container strongly reduced the risk of CLABSI in both cities ( $p$ values $<0.001$ ). The HR of susceptible admissions becoming infected with a CLABSI was between 0.15 and 0.31. In Mexico City and São Paulo, the closed infusion container significantly increased the hazard of moving from 'susceptible' to 'discharged', meaning that admissions tended to leave the ICU faster after its introduction. In Mexico, the closed infusion container significantly increased the

Table 2 Hazard ratios and $95 \%$ Cls for rates of transmissions by city

\begin{tabular}{|c|c|c|c|c|}
\hline \multirow{2}{*}{$\begin{array}{l}\text { Covariate } \\
\text { Transition }\end{array}$} & \multicolumn{2}{|l|}{ Mexico } & \multicolumn{2}{|l|}{ São Paulo } \\
\hline & HR $(95 \% \mathrm{Cl})$ & p Value & HR $(95 \% \mathrm{Cl})$ & p Value \\
\hline \multicolumn{5}{|l|}{ Age (10 years) } \\
\hline Susceptible $\rightarrow$ CLABSI & $0.87(0.81$ to 0.95$)$ & 0.001 & $1.03(0.91$ to 1.16$)$ & 0.67 \\
\hline Susceptible $\rightarrow$ Discharged & $0.98(0.95$ to 1.01$)$ & 0.13 & 0.99 (0.95 to 1.03$)$ & 0.62 \\
\hline Susceptible $\rightarrow$ Dead & $1.01(0.94$ to 1.07$)$ & 0.86 & 0.99 (0.92 to 1.06$)$ & 0.74 \\
\hline CLABSI $\rightarrow$ Discharged & $1.03(0.92$ to 1.15$)$ & 0.64 & $0.96(0.84$ to 1.09$)$ & 0.55 \\
\hline CLABSI $\rightarrow$ Dead & $1.01(0.89$ to 1.14$)$ & 0.90 & $1.12(0.87$ to 1.44$)$ & 0.39 \\
\hline \multicolumn{5}{|l|}{ ASIS score } \\
\hline Susceptible $\rightarrow$ CLABSI & $1.07(0.89$ to 1.28$)$ & 0.47 & $0.86(0.60$ to 1.23$)$ & 0.40 \\
\hline Susceptible $\rightarrow$ Discharged & $0.48(0.45$ to 0.51$)$ & $<0.001$ & $0.64(0.58$ to 0.71$)$ & $<0.001$ \\
\hline Susceptible $\rightarrow$ Dead & 2.01 (1.70 to 2.38$)$ & $<0.001$ & $0.98(0.79$ to 1.20$)$ & 0.81 \\
\hline CLABSI $\rightarrow$ Discharged & $0.54(0.41$ to 0.70$)$ & $<0.001$ & $0.76(0.47$ to 1.23$)$ & 0.27 \\
\hline CLABSI $\rightarrow$ Dead & $0.94(0.70$ to 1.26$)$ & 0.66 & $1.33(0.62$ to 2.87$)$ & 0.47 \\
\hline \multicolumn{5}{|l|}{ Closed versus open system } \\
\hline Susceptible $\rightarrow$ CLABSI & $0.15(0.08$ to 0.26$)$ & $<0.001$ & $0.31(0.16$ to 0.60$)$ & $<0.001$ \\
\hline Susceptible $\rightarrow$ Discharged & $1.24(1.10$ to 1.40$)$ & $<0.001$ & $1.53(1.31$ to 1.78$)$ & $<0.001$ \\
\hline Susceptible $\rightarrow$ Dead & $0.65(0.50$ to 0.84$)$ & $<0.001$ & $0.83(0.61$ to 1.11$)$ & 0.20 \\
\hline CLABSI $\rightarrow$ Discharged & $2.56(1.28$ to 5.12$)$ & 0.008 & $1.70(0.74$ to 3.91$)$ & 0.21 \\
\hline CLABSI $\rightarrow$ Dead & $0.77(0.24$ to 2.51$)$ & 0.67 & $1.88(0.46$ to 7.67$)$ & 0.38 \\
\hline
\end{tabular}

ASIS, acute severity of illness score; CLABSI, central line associated blood stream infection. 
Table 3 Difference in the number of infected and dead admissions, and the difference in total bed days for the open and closed systems based on 1000 simulated admissions with a central line

$\begin{array}{ll}\text { Mexico } & \text { São Paulo } \\ \text { Mean }(95 \% \mathrm{Cl}) & \text { Mean }(95 \% \mathrm{CI})\end{array}$

Numbers infected

Open system

Closed system

Difference*

Numbers dead

Open system

Closed system

Difference*

Bed days

Difference* $^{*}$
146 (76 to 266$)$

26 (9 to 61$)$

120 (62 to 213)

251 (102 to 395$)$

161 (47 to 294)

90 (27 to 158)

$34(-1211$ to 1246$)$
92 (37 to 182$)$

28 (8 to 73 )

64 (24 to 129)

267 (125 to 407$)$

187 (74 to 322$)$

81 (25 to 143 )

2693 (1152 to 4569$)$

Simulated for admissions of an average age and ASIS score.

*Open minus closed.

$\mathrm{Cl}$, credible interval.

rate of discharge for infected admissions (HR 2.56, $95 \%$ CI 1.28 to $5.12, \mathrm{p}=0.008$ ), whereas there was a non-significant increase in this rate in São Paulo. In Mexico, the closed infusion system reduced the risk of death prior to infection (HR $0.65,95 \%$ CI 0.50 to 0.84 , $\mathrm{p}<0.001)$.

Based on simulation results, the differences between the closed and open infusion systems in terms of the numbers of admissions infected with a CLABSI, deaths and total number of bed days, are shown in table 3 .

In both cities the number of infected admissions with a CLABSI was significantly less with the closed infusion container. The reduction in the number of infections was largest in Mexico (120 less infected admissions per 1000 admissions with a central line), which reflects the fact that it showed the largest reduction in hazard under the closed infusion container system (table 2). The closed infusion container also resulted in fewer deaths and in both cities this reduction was statistically significant. In Mexico there was very little change in the number of bed days, but in São Paulo there was a big reduction of 2693 bed days per 1000 admissions with a central line.

The number of admissions over time in each of the four states (based on the simulations) is shown in figure 2. The lines show the mean numbers in each state during the first 60 days. The reduction in CLABSI rates due the closed infusion container can be seen in the 0 to 20-day period and are shown on the graph as fewer individuals having a CLABSI. Because of this outcome, more patients are being discharged and there are fewer deaths; these outcomes are also shown by the lines in figure 2 .

\section{DISCUSSION}

From a clinician's perspective, the closed system might be superior to using semi-rigid glass or plastic bottles that are externally vented to allow the fluid to leave. These open systems were thought to be responsible for a large outbreak of gram-negative bacteraemia ${ }^{10}$ and smaller outbreaks ${ }^{11}$ from contaminated infusate. Other benefits for clinicians are less breakage, reduced weight, easier disposal and greater durability. ${ }^{12}$

A decision to adopt closed infusion containers is supported by the evidence revealed here of reduced rates of CLABSI in both cities. After adoption, the HR of susceptible admissions becoming infected with a CLABSI was 0.15 in Mexico City and 0.31 in São Paulo. This represents a reduction in risk of between three- and sevenfold. A higher ASIS score influenced risk in an intuitive way, by reducing the risk of discharge and increasing the risk of death. The results of the simulated data confirmed that the closed infusion container resulted in a clinically and statistically significant reduction in the number of CLABSIs. Based on 1000 admissions with a central line, we expect 120 less CLABSIs in Mexico and 64 less in São Paulo, a reduced number of deaths and in São Paulo a significant saving in bed days.

These findings are intuitive and easy to interpret for policy making. There are fewer infections and fewer deaths. There will also be cash savings from avoided consumables used to treat the infection. These savings must be balanced against the higher economic costs of implementing the closed infusion container system. All the other costs of running an ICU, such as staff time, capital equipment and buildings, and clinical and indirect overheads, will remain fixed regardless of the rate of CLABSI and so no other financial costs will change in the short term.

A major economic benefit of fewer infections is that bed days are released for other uses. These bed days will have a positive economic value if demand for ICU services exceeds supply. ${ }^{13} 14$ Their value depends on the preferences of decision makers who allocate scarce healthcare expenditures in each setting. If, for example, decision makers in São Paulo are willing to pay $\$ 300$ to access a marginal ICU bed day, ${ }^{15}$ then the economic value of the cost savings for the 1000 simulated admissions under a closed infusion container system is $\$ 807900$. These can be thought of as economic savings 


\section{Mexico}

\section{Open system}

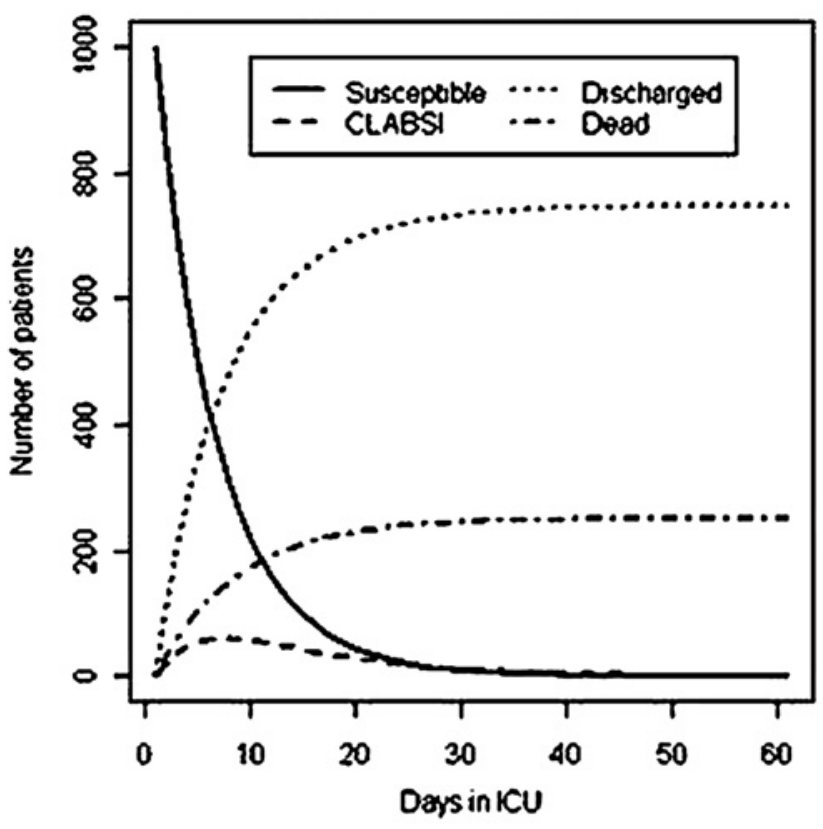

Closed system

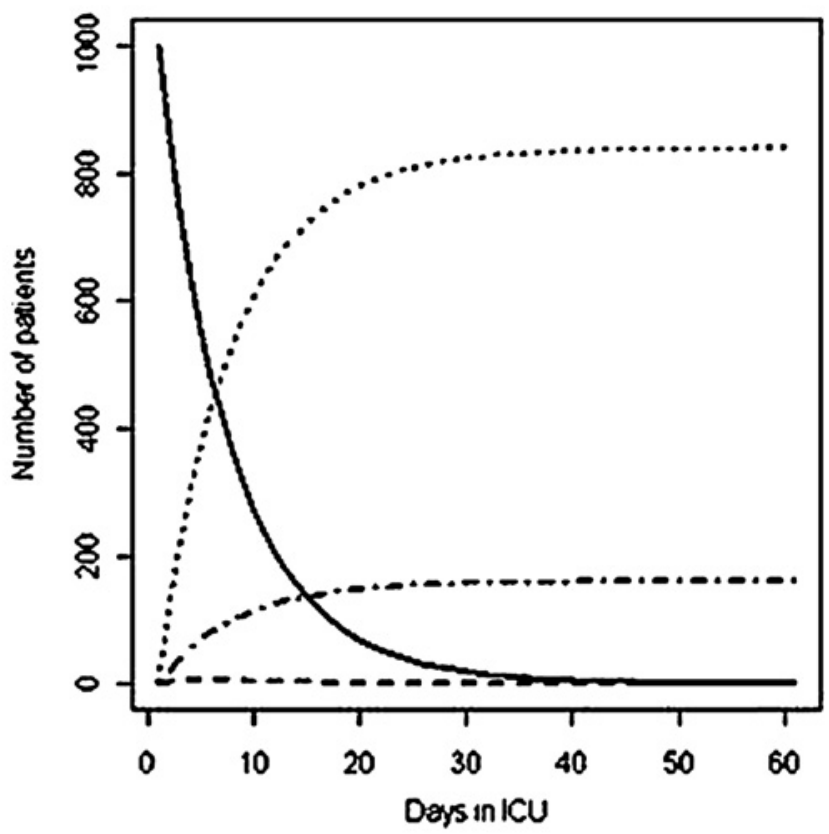

São Paulo
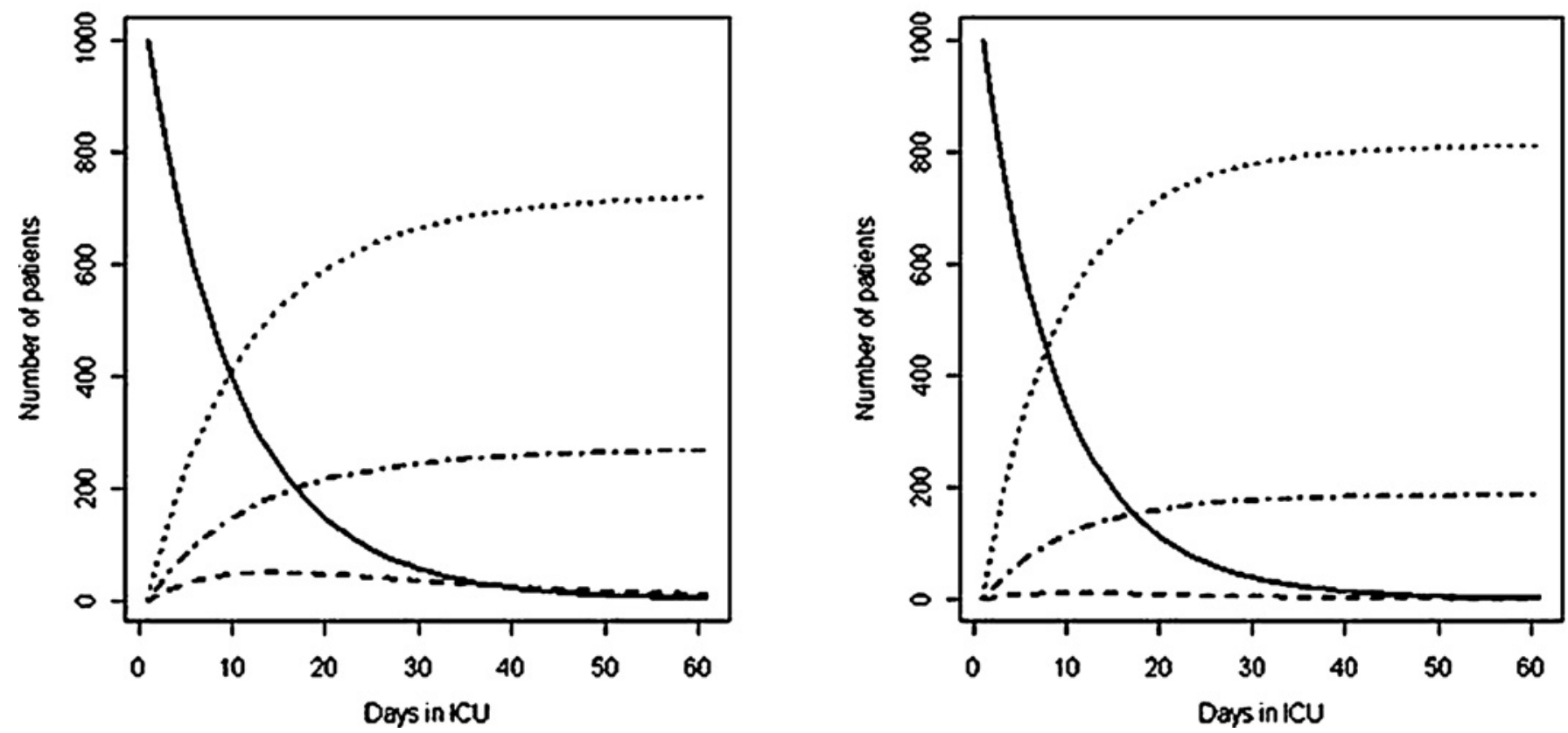

Figure 2 Numbers in each state over the first 60 days in an intensive care unit (ICU) in two cities based on 1000 simulated admissions with a central line. CLABSI, central line associated blood stream infection.

to offset the costs of adoption. With higher ICU throughput, there will of course be increased variable costs from treating new admissions. ${ }^{10}{ }^{11}$ In addition to changes in costs, there will be large health benefits from fewer deaths. The average age of the São Paulo cohort was 54 years (table 1); if an extra 18 years of life results from an avoided death, then 1458 years of life will be gained.
A complete economic analysis would consider the full implementation costs of a closed system, how much these are offset by cost savings from reduced infections, and the extra quality adjusted life years gained. This analysis does not show all these outcomes. However, findings do support the idea that CLABSI increases risk of death and is costly as it prolongs length of hospital stay. A decision to adopt the closed infusion container in 
Mexico and São Paulo could potentially reduce costs and generate health benefits.

Acknowledgements We acknowledge the many healthcare professionals who helped make these studies possible.

Correction notice The "To cite: ..." information and running footer in this article have been updated with the correct volume number (volume 1).

Funding This work was supported by Baxter Healthcare Corporation, Baxter, S.A. de C.V. in Mexico and Baxter Hospitalar Ltda. in Brazil. Baxter also provided Viaflex closed infusion containers.

Competing interests None.

Contributors VR organised data collection. NG, AB and VR performed all data analyses and contributed to drafting of the manuscript. $N G, A B$ and $V R$ wrote/checked the manuscript.

Provenance and peer review Not commissioned; externally peer reviewed.

Data sharing statement No additional data available.

\section{REFERENCES}

1. Rosenthal VD, Graves N, Maki DG. The International Nosocomial Infection Control Consortium (INICC): goals and objectives, description of surveillance methods, and operational activitie. $A m J$ Infect Control 2008;36:e1-12.

2. Rosenthal VD, Maki DG. Prospective study of the impact of open and closed infusion systems on rates of central venous catheterassociated bacteremia. Am J Infect Control 2004;32:135-41.

3. Bartlett MS. An Introduction to Stochastic Processes, with Special Reference to Methods and Applications. Cambridge, New York: Cambridge University Press, 1978.
4. Crnich CJ. Estimating excess length of stay due to central lineassociated bloodstream infection: separating the wheat from the chaff. Infect Control Hosp Epidemiol 2010;31:1115-17.

5. Beyersmann J, Kneib T, Schumacher M, et al. Nosocomial infection, length of stay, and time-dependent bias. Infect Control Hosp Epidemiol 2009;30:273-6.

6. Barnett AG, Beyersmann J, Allignol A, et al. The time-dependent bias and its effect on extra length of stay due to nosocomial infection. Value Health 2011:14:381-6.

7. Beyersmann J, Gastmeier P, Grundmann $\mathrm{H}$, et al. Use of multistate models to assess prolongation of intensive care unit stay due to nosocomial infection. Infect Control Hosp Epidemiol 2006;27:493-9.

8. Putter H, Fiocco M, Geskus RB. Tutorial in biostatistics: competing risks and multi-state models. Stat Med 2007;26:2389-430.

9. Lunn D. Differential Interface-Worked Examples, Technical Report WinBUGS. London, UK: Dept. Epidemiology and Public Health, Imperial College. (http://www.winbugs-development.org.uk/wbdiff.html).

10. Maki DG, Rhame FS, Mackel DC, et al. Nationwide epidemic of septicaemia caused by contaminated intravenous products. I. Epidemiologic and clinical features. Am J Med 1976;60:471-85.

11. Maki DG, Anderson RL, Shulman JA. In-use contamination of intravenous infusion fluid. Appl Microbiol 1974;28:778-84.

12. Maki DG, Rosenthal VD, Salomao R, et al. Impact of switching from an open to a closed infusion system on rates of central lineassociated bloodstream infection: a meta-analysis of time-sequence cohort studies in 4 countries. Infect Control Hosp Epidemiol 2011;32:50-8

13. Graves N, Halton $\mathrm{K}$, Lairson D. Economics and preventing hospital acquired infection: broadening the perspective. Infect Control Hosp Epidemiol 2007;28:178-84.

14. Graves N. Economics and preventing hospital-acquired infection Emerg Infect Dis 2004;10:561-6.

15. Salomao R, Grinberg G, Nouer S, et al. Extra length of stay and device-associated nosocomial infection rates in intensive care units in three hospitals of Brazil. In: ICAAC Meeting; 16-19 December 2005 Washington DC, USA, 2005 